\title{
LA BELLEZA EN LA FEALDAD EN LA OBRA DE ALAIN PLATEL
}

\section{Natalia Monge Gómez}

Universidad del País Vasco / Euskal Herriko Unibertsitatea. Dpto. Didáctica de la Expresión Musical, Plástica y Corporal

\begin{abstract}
Resumen
Distintas teorías estéticas han considerado lo feo como antítesis de lo bello, pero lo que todas estas teorías reconocen, es el principio según el cual el arte tiene el poder de representar aquello considerado feo de manera hermosa, y esa belleza permite aceptar lo feo o grotesco. En el ámbito de las artes escénicas, el director de escena Alain Platel propone un cambio del paradigma de la estética de la belleza en la danza en el que introduce una mirada diferente e incluye otro tipo de movimientos fuera del abanico de los considerados propios del vocabulario de la danza. Encuentra la belleza en lo que comúnmente es percibido como grotesco, desviado, anormal, discordante y en lo que a menudo se ve como enfermedad o síndrome. Inspirado por el mundo de los discapacitados descubre su interés por el poder emocional de lo deforme y busca así un lenguaje físico al que él llama "la belleza en la fealdad".
\end{abstract}

Palabras-clave: DANZA; BELLEZA; FEALDAD; ESTÉTICA; LENGUAJE CORPORAL

\section{Abstract}

Different aesthetics theories have considered the ugliness as opposite of the beauty, but all these theories recognize the principle that the art has the power of representing in a beautiful way what is considered as ugly, and that beauty allows accepting the ugliness or grotesque. In the field of Performing Arts the scene director Alain Platel proposes a change in the dance beauty aesthetics paradigm and he introduces a new optics and includes another kind of movements out of the range of dance vocabulary. He finds beauty in what is usually conceived as deform, distort, unusual, discordant and in what is often considered as an illness or syndrome. Inspired by the world of disabled people, he discovers his interest in the emotional power of the deformity and looks for a physical language that he calls himself "the beauty in the ugliness".

Keywords: DANCE; BEAUTY; UGLINESS; AESTHETICS; BODY LANGUAGE

\footnotetext{
Monge Gómez, Natalia. 2015. "La belleza en la fealdad en la obra de Alain Platel”. AusArt 3 (1): 9-21. D0I: 10.1387/ausart.14750
}

\section{AUSART}




\section{CONCEPCIONES DE LA \\ BELLEZA Y LA FEALDAD EN EL ARTE}

A lo largo de la historia distintas teorías estéticas han considerado lo feo como antítesis de lo bello, como una ausencia de armonía que rompe las reglas de la proporción en las que se basa la belleza, tanto física como moral, o como una carencia que despoja al ser lo que debería tener por naturaleza. Según la teoría de los griegos, un defecto o disonancia perturba totalmente la armonía básica de la belleza corporal y mental. Sin embargo, todas estas ideas de belleza reconocen un principio, según el cual, el arte es capaz de representar aquello considerado feo como algo bello, y esa belleza permite aceptar lo feo o grotesco.

La relación entre belleza y arte se ha planteado de forma ambigua porque, aun privilegiando la belleza de la naturaleza, se admitía que el arte podía representar la naturaleza de una forma bella, incluso cuando la naturaleza representada fuese en sí misma peligrosa o repugnante (Eco 2004). En su tratado "Historia de la belleza", Umberto Eco declara que ya en la Edad Media se había expuesto el problema de una representación bella del diablo, y esta cuestión se retomará con toda su fuerza en

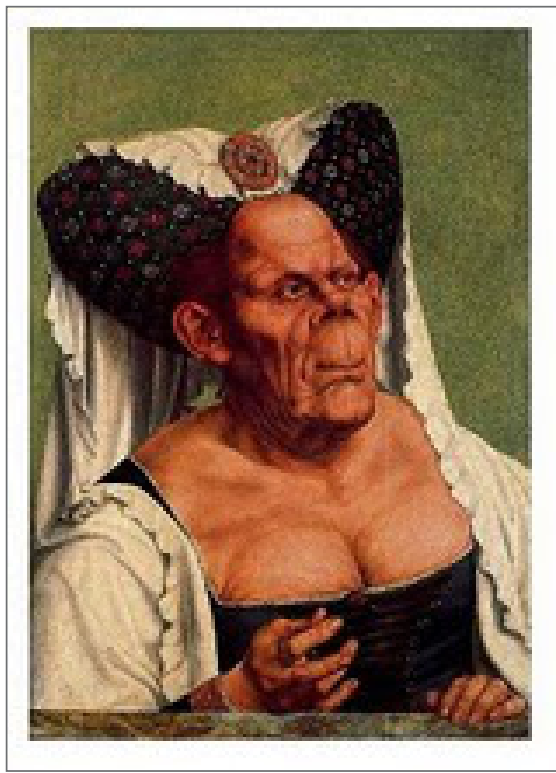

Fig. 1. La duquesa fea (1523-1530), Quentin Metsys. la época romántica. No es fortuito que, en la época clásica tardía y sobre todo en la era cristiana, la problemática de lo feo se vuelva más compleja.

En 1853 se publica "Estética de lo feo" de Karl Rosenkranz que supone un momento intermedio de la estética del siglo XIX. Retoma la idea tradicional de que lo feo es lo contrario de lo bello, pero según su teoría la fealdad es necesaria en el arte, como elemento de la realidad, porque lo bello depende de lo feo y viceversa.

Asumiendo la representación artística de lo feo, confecciona una extensa serie de síntomas de la fealdad del arte tales como: el alejamiento definitivo de la pintura del canon clásico, la representación escultórica de la lujuria, 
la incipiente fotografía o la frivolización de la ópera (Rosenkranz 1853).

Tras "Historia de la belleza", Eco escribe "Historia de la fealdad" (2007). Recorre un itinerario por tres mil años de pesadillas y terrores, donde los sentimientos de repulsa y de conmovedora compasión se acercan. Entre demonios, locos y deformidades que rozan lo sublime, descubre una vena iconográfica considerablemente amplia e insospechada. $Y$ es que ya Kant declaraba que el más alto vuelo que tomó el genio humano para llegar a lo sublime consistía en extravagancias (Kant 1919). La asimetría, la falta de armonía y la deformidad, lo banal, casual, arbitrario, tosco, grotesco, repulsivo o lo lamentable configuran toda una

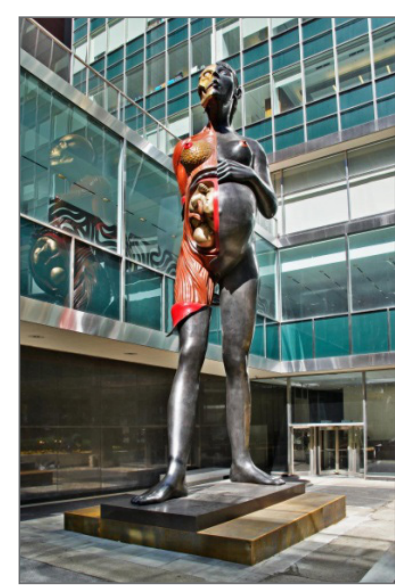

Fig.2. The virgin mother (2005) Damien Hirst. paleta de bellezas en fealdades.

En el siglo XX autores como Picasso y Bacon dinamitaron, con las figuras distorsionadas de sus obras, los cánones estéticos. El agotamiento del canon de belleza clásico, las nuevas búsquedas, el mestizaje y la globalización facilitaron la democratización de la fealdad. Esta popularización de lo feo y el feísmo se recuerda en la exposición de Lucerna "Picasso versus Bacon: cara a cara" (Carrizo 2007).

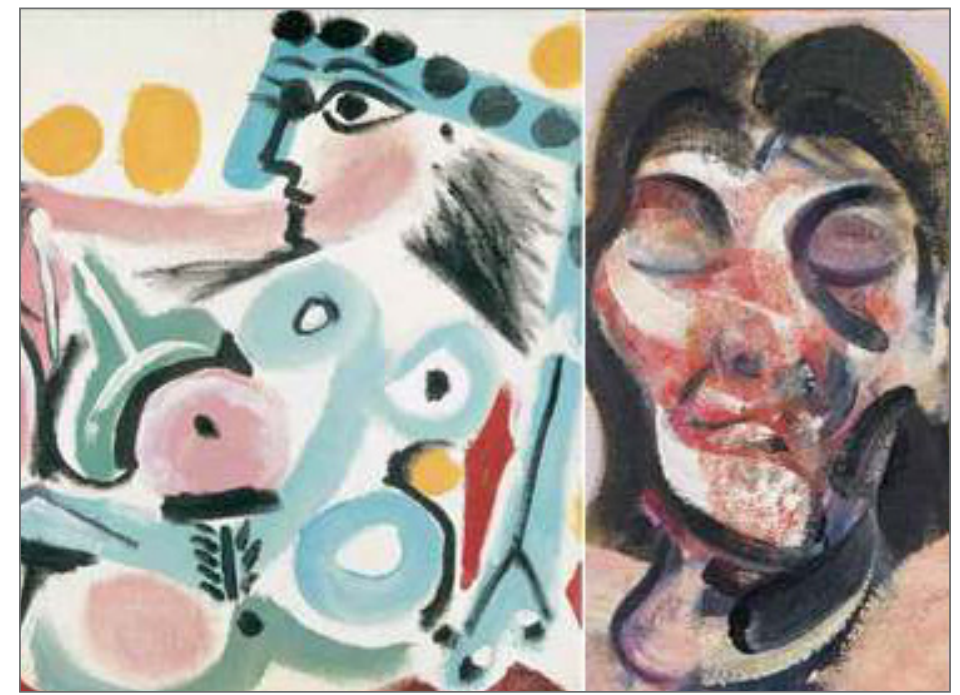

Fig.3. Nu assis (1964), Picasso.

Fig.4. Three studies for Portrait of Henrietta Morales (1969), Bacon. 
En el ámbito de las artes escénicas el director de escena Alain Platel plantea una nueva óptica de la danza en la que introduce una mirada diferente a partir de su interés por el poder emocional de lo deforme, a lo que él llama "la belleza en la fealdad".

\section{UNA ESTÉTICA PARTICULAR: LA BELLEZA EN LA FEALDAD}

A partir de su pieza Vsprs (2006) Platel comienza la búsqueda de un lenguaje físico específico. Conecta su búsqueda con el mundo de los discapacitados y encuentra una nueva vía de expresión descubriendo la belleza en contextos que a priori no estaban conectados en absoluto con lo bello. Un concepto que él mismo denomina "la belleza en la fealdad". De hecho, es una parte muy básica y profundamente arraigada de sus principios estéticos. Sin entender la base de esta estética en la que él cree profundamente, es difícil comprender el sentido de sus obras. Propone un cambio del paradigma de la estética de la belleza en la danza y con ello da la vuelta a muchos conceptos concebidos canónicamente hasta entonces.

Encuentra la belleza en lo que comúnmente es percibido como feo o grotesco, desviado, anormal, discordante y en gestualidades que a menudo se conciben como enfermedades o síndromes tales como espasmos, calambres, convulsiones, tics... toda una gama de tensiones musculares raras o poco comunes.
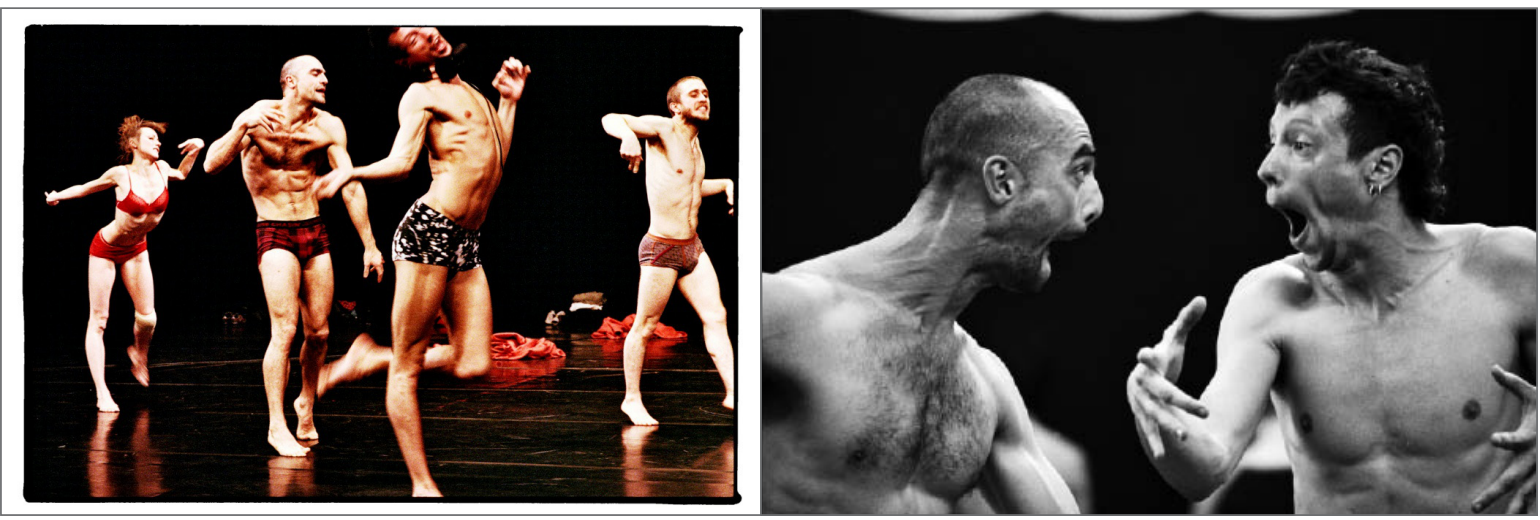

Fig. 5 y 6. Out of Context-for Pina (2010), Platel. 
Platel nos fuerza a mirarlos de una manera diferente. El lenguaje, los movimientos plásticos que propone no son considerados como parte de un amplio vocabulario de la danza, a los que él les da un valor diferente y descubre la profunda humanidad de lo que tenemos en común con gente con la que a priori no parece que compartamos nada.

La noción de estética de Platel invita a cuestionar los códigos de referencia de una concepción académica de la belleza y las representaciones estéticas dominantes. Con su danza se transgreden los hábitos coreográficos y se crean nuevas referencias poéticas y rituales de agitación visual, donde se dan inestabilidades e, incluso, incongruencias.

Betty Mercier-Lefèvre se cuestiona si se trata de una cuestión artística o si puede expresar una aproximación crítica de valores sociales y culturales establecidos. Al mismo tiempo, plantea si la danza puede redefinir el cuerpo como una experiencia de los sentidos, como una emoción a compartir (Mercier-Lefèvre 2007).

Platel estudia psicología y pedagogía y llega al teatro de manera accidental. En un principio no reconoce la conexión de ambos mundos, sin embargo, en una segunda etapa de su obra ${ }^{1}$ afloran todas las inquietudes que provienen de su formación como psicopedagogo. Platel está obsesionado por esos mundos que descubre en sus estudios y, sobre todo, en su experiencia laboral en un hospital psiquiátrico infantil y un centro para niños con parálisis cerebral (Longuet 2010). Trabajando con personas que tienen problemas físicos extremos, encuentra algo de lo que no ha sido consciente hasta entonces; algo específico que para él tiene que ver con la sensibilidad y con el hecho de que el cuerpo adquiere el protagonismo cuando ya no se puede hablar sobre determinadas cosas.

En este segundo periodo, al trabajar sus piezas escénicas, siempre persigue estos elementos que en el primer periodo no buscaba de una manera tan consciente. Sin embargo, al hallar las imágenes específicas en diversos documentales todo comienza a definirse y puede ser mucho más explícito. Encuentra esas imágenes en uno de sus lugares favoritos en su Gante natal, el museo Dr. Guislain, que tiene conexión con un hospital psiquiátrico. En este museo realizan exposiciones asombrosas en las que no sólo muestran toda la historia del psiquiátrico visualmente, sino que conectan el centro con el arte contemporáneo y el arte realizado por personas con dificultades severas o que 
residen en hospitales psiquiátricos. Platel declara: "creo que es el arte más bello que puede existir en el mundo" (Cools 2012).

En una de las exposiciones del museo Dr. Guislain encuentra una proyección de un film que llama poderosamente su atención. Se trata de un documental del psiquiatra Arthur van Gehuchten ${ }^{2}$ de principios del siglo XX que le sorprende al descubrir la posible relación entre los movimientos de los pacientes, sus gestos, sus comportamientos y la danza. Cuando Platel ve aquellas imágenes tan extremas, decide mostrárselas a los intérpretes para observar sus reacciones. Sabe entonces que es el principio de algo con lo que aún sigue trabajando en la actualidad.

Con el grupo de intérpretes con los que comienza a trabajar desde Vsprs quiere saber cómo interpretarían ellos mismos esas imágenes. Las personas que aparecen en las imágenes son descritas como enfermas, pero para él eso es inconcebible, porque precisamente ve a esas personas como gente extremadamente sensible. Para Platel la gente discapacitada ya está bendecida por una cierta hipersensibilidad, una sensibilidad hacia la vida, algo que les hace ser conscientes del mundo de alrededor (Platel \& Cope 2010). Imagina que ese tipo de comportamientos extremos funcionan como posible vía de comunicación y afirma que hay un verdadero deseo por parte de los intérpretes de vivir esas experiencias, por ejemplo en el contexto de buscar esos estados en los que moverse es una experiencia de éxtasis.

Para Platel, el sufrimiento es una parte muy esencial de la condición humana y donde todos somos iguales; es únicamente entonces cuando la comunicación real y profunda puede suceder. Mostrar este sufrimiento siempre ha sido un tema fundamental en la historia del arte. Ejemplo de ello son conceptos que cobran gran importancia con la llegada de la sensibilidad cristiana y el arte que la expresa como: el dolor, el sufrimiento, la muerte y las deformaciones físicas (Eco 2007). Platel quiere descubrir si investigando en ese vocabulario en el que trabajan, se pueden lograr nuevos estratos o estratos diferentes de comunicación relacionados con la cuestión del sufrimiento. 


\section{FUENTES DE INSPIRACIÓN \\ DE SU TRABAJO}

Comienza a desarrollar esta particular manera de mirar cuando trabaja con personas con discapacidades físicas o mentales en su etapa de psicopedagogo. En aquel tiempo queda impresionado por los trabajos de Fernand Deligny (1913-1996) y por sus emprendedores puntos de vista en el campo del autismo. Este pedagogo francés es pionero en su radical acercamiento al tratamiento de niños con autismo. Deligny hace un esfuerzo incomparable en permitir al otro ser diferente y en encontrar destellos de complicidad en cada encuentro o enfrentamiento. No tiene miedo a buscar las partes oscuras y misteriosas en cada momento, y su vida está marcada por una absoluta confianza en el otro y por el alivio de que la conexión es posible, incluso si el lenguaje fracasa.

Platel es un acérrimo defensor de la humanidad colectiva, pese a la naturaleza de los individuos, ya que todos estamos sujetos a la muerte, al sexo, y a sentimientos de pérdida y de deseo ${ }^{3}$. No parece ilógico relacionar entonces los ideales de Platel en su forma de trabajar y en su utopía de vivir en comunidad con los principios de Deligny. En Out of context-for Pina vuelve específicamente a Deligny e incluye otras enfermedades como la corea, un complejo trastorno neurológico.

También se inspira por artistas visuales o escultores como Berlinde De Bruyckere. Esta escultora, también gantesa, es una gran influencia en el trabajo de Platel. Así, las fotos de sus impactantes obras han estado siempre presentes en la pared del estudio durante los procesos de muchas de sus piezas.

De Bruyckere juega con la expectativa que se tiene de un cuerpo, lo distorsiona y elimina los pilares alrededor del concepto de identidad: los órganos sexuales y el rostro. La ausencia de identidad facial, en combinación con una interpretación del cuerpo como una entidad que representa la permanente lucha entre la forma y la abstracción, son los elementos que sustentan el discurso de De Bruyckere. A través de elementos naturales como cera, madera, lana, piel y pelo

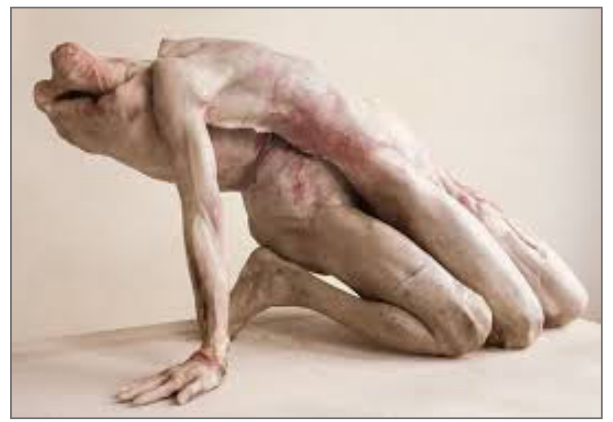

Fig. 7. Into One-Another III, (2010). Bruyckere. 


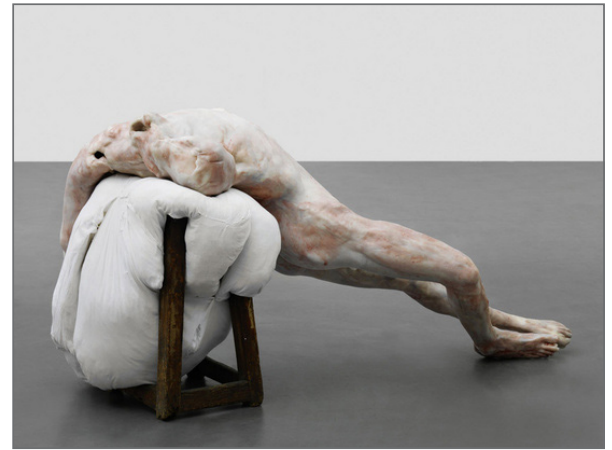

Fig. 8. Romeu, 2010 (2010), Bruyckere. del caballo crea una especie de paraíso imperfecto que dispone a enfrentarse al mundo de lo físico como algo relativo ${ }^{4}$.

Su trabajo se ha descrito como brutal y difícil, sin embargo, algunos lo ven como reconfortante y poético, esculturas que muestran la vulnerabilidad pero, a pesar de todo, invitan a ver más allá del ideario colectivo, piezas que aseguran que somos más que carne.

\section{LENGUAJE CORPORAL PROPIO DE SU OBRA COREOGRÁFICA}

Según Rudi Laermans, el aspecto más crucial en diversas tendencias de la escena contemporánea es el humanismo corpóreo de la danza (Laermans 2010). Considera que el cuerpo humano es el lugar, así como el primer canal de comunicación de verdades fundamentales de la condición humana. Y mientras otros autores insisten en las legítimas capacidades expresivas del movimiento físico, Platel enfoca su trabajo en los límites del cuerpo como una técnica de comunicación y representación, sin abandonar un sentido humanista subyacente.

Laermans afirma que para Platel el cuerpo es una técnica de expresividad no verbal que se convierte en algo eminente como tal sólo cuando el deseo de expresar algo es obstaculizado por el mismo cuerpo. A esta concepción del movimiento la denomina "danza gesticulada", la cual revela el cuerpo como una técnica genuina por la misma inhabilitación de habilidades habituales de la expresividad y la comunicación no verbal.

Platel se cuestiona qué nos queda cuando las palabras no son suficientes para expresar los sentimientos más profundos y encuentra la respuesta en el cuerpo. Afirma: "Mi danza ha sido siempre la búsqueda de un lenguaje físico capaz de expresar el inconsciente, esas cosas que definitivamente las palabras ya no pueden expresar" (Caballero \& Khan 2012, 28). En definitiva, tiene 
gran fe en el poder del cuerpo humano como herramienta emocional y transmisora de la memoria.

Hildegard de Vuyst, dramaturga que colabora con Platel desde hace más de dos décadas, subraya la manera en la que combina las cosas de forma que cada declaración se convierte en una historia con varias caras. Señala también la manera en la que juega con símbolos e identidades, sin allanar o borrar contrastes y sin recurrir al relativismo cultural. "Viendo a través de tus ojos aprendí a ver belleza donde antes nunca la hubiese visto" (Platel 2006, 135).

En cuanto a la calidad de movimiento, en este lenguaje específico del que se va apropiando a lo largo de las últimas creaciones, explora todo un rango de movimientos espasmódicos, contraídos, apretados, impulsivos e histéricos. Relaciona estas calidades de movimiento con diferentes concepciones. Así, en Vsprs (2006) se trata del lenguaje de la pérdida de uno mismo, en Nine Finger (2007) traslada ese vocabulario al sufrimiento de un niño de guerra africano, en pitié! (2008) surge la cuestión del sacrificio del individuo por el grupo, en Out of Context - for Pina (2010) se aproxima a la autosatisfacción o realización personal, en $C(h) o e u r s ~(2012)$ se dibuja la disyuntiva entre el individuo y el colectivo y en Tauberbach (2012) se viaja hacia la supervivencia del ser humano en condiciones precarias.

Por su parte Josette Féral (2014), declara que Platel busca el gesto del cuerpo desgarbado, a menudo deformado en convulsiones, jadeante, sumiso a la tirantez de los miembros, a veces cuerpo mecanizado más que cuerpo maestro y armónico. Se trata de gestos en los que el espectador percibe la inspiración de los cuerpos que sufren; cuerpos histéricos en extrañas posturas que rompen la armonía de sus miembros; cuerpos presos de convulsiones que se transforman en gesto artístico. Curiosamente a través de ese universo de movimientos histéricos se transmite la humanidad que tanto obsesiona al creador para conectar con el espectador. Esta falta de armonía del cuerpo y la humanidad que emana interpela al espectador, le cuestiona acerca de la naturaleza de la seducción estética ejercida en este excéntrico universo y el placer sentido por el público.

Por otro lado, el concepto de reciclaje es, según Féral, uno de los fundamentos del arte de Platel. Se materializa tanto en el reciclado de materiales, la ropa en Tauberbach, o la escenografía en Vsprs, como en el de gestos prestados por otros universos, incluyendo el de las enfermedades mentales o físicas. 

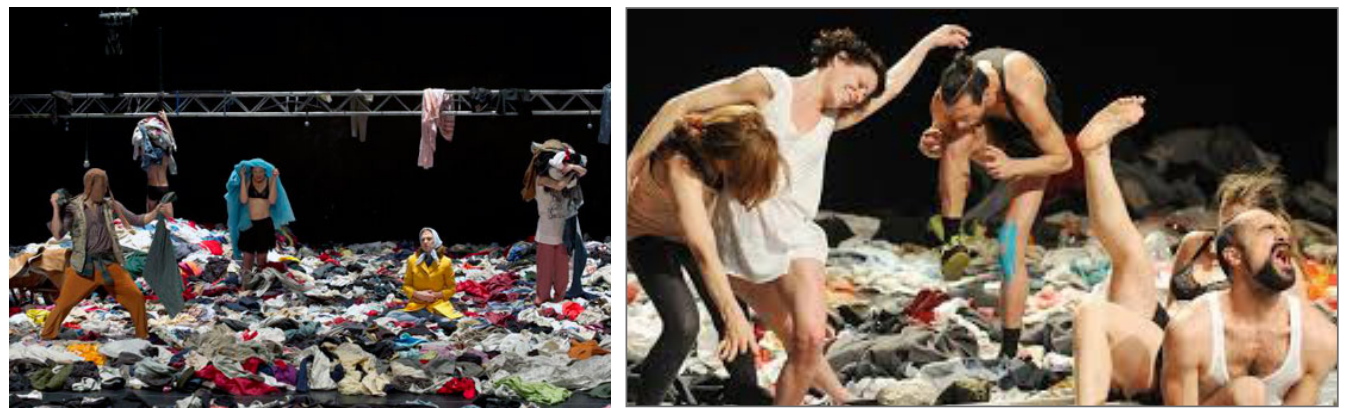

Fig. 9 y 10. Tauberbach (2014), Platel.

Platel genera un espacio corpóreo singular que despliega todo un mundo sensorial en el espectador. Estas sensaciones atestiguan la propia existencia gracias a la experiencia sensorial, que nos concede la oportunidad de empatizar con los intérpretes. Esta experimentación del observador activo supone una práctica distinta a la habitual, enfrentando de esta manera al espectador hacia otra percepción de su propio yo (Merlau-Ponty 1945).

\section{CONCLUSIONES}

A partir de su concepción de "la belleza en la fealdad", Platel plantea una nueva óptica en la que introduce una mirada diferente. Una mirada que incluye otro tipo de movimientos no al uso, fuera del abanico de movimientos considerados propios del vocabulario de la danza. Con la gestualidad y el lenguaje corporal que sugiere va más allá de los cánones de belleza establecidos en la danza y encuentra su forma de belleza inspirado en el poder emocional de lo deforme, especialmente en seres diferentes. Busca una manera de comunicación a través de su lenguaje no verbal para expresar el sufrimiento, el que para Platel, es el denominador común del ser humano.

Los gestos tomados de la vida cotidiana; a menudo signos de discapacidad, de malestar, de personas que luchan con una gestión problemática de la realidad, se repiten en un contexto artístico. Se multiplican, amplifican y se dotan a través de sus bailarines de una nueva fuerza que obliga al espectador a mirar de otra manera, a centrarse tanto en su virtuosismo como en estas nuevas imágenes. Lejos de eclipsar los vínculos que estos gestos conservan con sus 
orígenes, no destruyen las viejas referencias, sino que las enriquecen con un nuevo significado que las engloba y unifica. Platel, genera así su historia de la belleza en la danza.

\section{Referencias}

Carrizo, Rodrigo. 2007. "Bacon y Picasso se ponen cara”. El País, 16 de agosto

Danto, Isabelle. 2011. "L'invention flamande sur scène". Esprit 3: 264-7

Eco, Umberto. 2004. Historia de la belleza. Barcelona: Lumen

- 2007. Historia de la fealdad. Barcelona: Random House

Féral, Josette. 2015? "Alain Platel ou la configuration du banal". Ponencia inédita presentada en Colloque International Alain Platel (Arras, 2014)

Kant, Immanuel. (1764) 1919. Lo bello y lo sublime: Ensayo de estética y moral. Barcelona: Calpe

Laermans, Rudi. 2010. "Impure gestures towards 'Choreography in General': re/presenting Flemish Contemporary Dance, 1982-2010". Contemporary Theatre Review 20(4): 405-15

Longuet Marx, Anne. 2010. "La communauté en scène". Pp. 141-51 en Théâtre et danse: Un croisement moderne et contemporaine. Vol. 1, Filiations historiques et positions actuelles, textes réunis par Philippe Ivernel et Anne Longuet Marx. Études théâtrales 49. Louvain-LaNeuve: Université Catholique de Louvain

Mercier-Lefèvre, Betty. 1999. "La danse contemporaine et ses rituels: L'exemple d'un spectacle d'Alain Platel". En: "Corps, Sport et Rites", $n^{\circ}$ monográfico, Corps et Culture 4. http://corpsetculture.revues.org/607

Merleau-Ponty, Maurice. (1975) 1994. Fenomenología de la percepción. Trad. Jem Cabanes. Barcelona: Península

Platel, Alain. 2006. Les Ballets C[ontemporains] de la B[elgique]. Tielt, Bélgica: Lannoo Uitgeverij

Platel, Alain. 2012. "Les ballets C[ontemporains] de la B[elgique]". Entrevista por Mercedes L. Caballero y Omar Khan. SusyQ 37: 20-43, http://susy-q.es/web susy/susyq 37.htm

Platel, Alain. 2012. Body: language Booklet \#7 Alain Platel. Entrevista por Guy Cools. London: Sadler's Wells

Platel, Alain \& Lou Cope. 2010. "Looking inward, outward, backward and forward". Contemporary Theatre Review 20 (4): 416-20

Rosenkranz, Karl. (1853) 1992. Estética de lo feo. Ed. y trad. Miguel Salmerón. S.I.: Julio Ollero 
Notas

${ }^{1}$ Después de Wolf (2003), Platel se aleja de la escena por unos años, y tras su vuelta cambia de temática. En vez de tomar como punto de partida la identidad socio-político-cultural de los intérpretes, busca algo del ser humano que se pueda representar y en tanto que espectadores nos podamos ver reflejados: hablar acerca de lo interior más que de lo exterior. Para ello hace uso de dos herramientas fundamentales: la música religiosa y un lenguaje físico específico, el cuerpo en estado de histeria. Ambas se convierten en las herramientas de partida de la realización de sus dos siguientes piezas Vsprs (2006) y pitié! (2009).

${ }^{2}$ Arthur van Gehuchten (1861-1914) fue profesor de Medicina en Lovaina y más tarde en Cambridge. Empezó a filmar a pacientes neurológicos en 1905 y usaba las grabaciones con fines educativos así como de diagnosis y documentación.

${ }^{3}$ www.lesballetscdelabe.be

${ }^{4}$ http://culturacolectiva.com/berlinde-de-bruyckere-el-cuerpo-es-relativo/ 